\title{
LUT
}

University

\section{Public relations and expectation theory: Introducing Relationship Expectation Theory (RET) for public relations}

\author{
Olkkonen Laura, Luoma-aho Vilma
}

This is a Author's accepted manuscript (AAM) version of a publication published by De Gruyter Mouton

in Public Relations

DOI: $10.1515 / 9783110554250-028$

Copyright of the original publication: (c) 2021 Walter de Gruyter GmbH, Berlin/Boston

Please cite the publication as follows:

Olkkonen, Laura and Luoma-aho, Vilma. "28 Public relations and expectation theory: Introducing Relationship Expectation Theory (RET) for public relations". Public Relations, edited by Chiara Valentini, Berlin, Boston: De Gruyter Mouton, 2021, pp. 541-562. https://doi. org/10.1515/9783110554250-028

The final publication is available at https://www.degruyter.com/document/ doi/10.1515/9783110554250-028/html

This is a parallel published version of an original publication. This version can differ from the original published article. 


\title{
28 Public relations and expectation theory: Introducing Relationship Expectation Theory (RET) for public relations
}

\begin{abstract}
Expectations provide organizations with information and cues about their stakeholders' and publics' values, interests, experiences, and knowledge. This chapter argues for a move that takes expectations beyond the current cursory level for different areas of public relationsreputation management, corporate responsibility, issues management, and legitimacy-toward explicit theoretical understanding and models for addressing expectations. The chapter introduces expectations as an intersecting phenomenon in public relations research and builds postulations for theorizing expectations in public relations by reviewing theories that address expectations in relationships, and by exploring different conceptual meanings of expectations. As a result, the chapter introduces Relationship Expectation Theory (RET) that places expectations in the domain of public relations. RET acknowledges different expectation types, the context of organizational relations, and organizations' limited ability to influence expectations.
\end{abstract}

Keywords: expectations, expectancies, Relationship Expectation Theory 


\section{Introduction}

This chapter discusses the relevance of existing expectation theories for public relations and sets forth Relationship Expectation Theory (RET) to explain expectations in the context of public relations. In existing research of public relations, expectations are widely referred to as factors explaining reputations, corporate responsibility, relationships, legitimacy, and trust, which are some of the most important and widely studied areas of research in the field (Olkkonen and Luomaaho 2015; Olkkonen 2015a). Expectations are further connected to central areas of the public relations function, such as issues management (e.g., Jaques 2009; Reichart 2003), relationship management (e.g., Coombs 2000; Ledingham 2003), reputation management (e.g., Eisenegger 2009; Fombrun and Rindova 1998), and crisis management (e.g., Coombs 2000; Brønn 2012) (see Olkkonen and Luoma-aho 2014 for a review). The ability to identify stakeholder expectations is also important for public relations practitioners (e.g., Global Alliance for Public Relations and Communication Management 2012), and the field itself continues to face pressing expectations stemming from its history in unethical practices such as manipulation (e.g., L'Etang and Pieczka 2006; L'Etang et al. 2016). In essence, public relations is expected to prove that it can and will add value for society at large — and bring transparency to the related practices, interests, and tensions.

Expectations relate to public relations research and practice especially in the sense that expectations provide organizations with information and cues about their stakeholders' and publics' values, interests, experiences, and knowledge. In other words, by understanding the expectations that stakeholders and publics have at a given point of time, organizations can assess their potential impacts on relationships, and possibly also learn about signals that assist in anticipating expectations' future direction. Considering the importance of expectations across 
many areas of public relations theory and practice, we argue in this chapter that expectations are best understood with explicit theoretical understanding and by employing models that explain how they unfold in various stages of relationships.

To build our argument and theory, we begin the chapter by discussing how expectations are currently connected to public relations research. Second, we review predominantly micro-level theories on expectations to explain how expectations affect the very core area of public relations: relationships. This review provides a comprehensive examination of expectations in relationships, starting from relationship entry (social exchange theory and expectancy value theory), moving on to interaction in relationships (symbolic interactionism and expectation states theory) and finally to relationship outcomes and continuation (expectancy disconfirmation theory, the gap model, and expectancy violations theory). In the third step, we dissect the concept of expectations by elaborating on the different meanings attached to it. For this, we review literature from social psychology, interpersonal communication, and customer management research to build a strong understanding of the concept of expectations - the fundamental building block for our theory development (cf. Walker and Avant 2011; Gioia, Corley, and Hamilton 2013). The concept, as we demonstrate, includes positive and negative, as well as predictive and normative elements.

Toward the end, the chapter presents our theorization of expectations in public relations as two-fold assessments of the outcomes the stakeholders or publics value and the confidence they place in an organization. We formulate our synthesis as Relationship Expectation Theory that acknowledges different types of expectations, the context of organizational relations, and organizations' limited ability to influence expectations, especially when they are based on values. We suggest that by theorizing expectations in public relations, we can add to the stream of public 
relations research that focuses on less organization-centric approaches and sees stakeholders and publics as cocreators of relationships, meaning, and communication (Botan \& Taylor 2004). We also discuss expectation analysis from a practical perspective and assess how it can connect to areas such as organizational monitoring and listening, with overarching connections to more strategic (and sometimes suspicious) attempts to prime and frame communication. We conclude that theorizing expectations can connect with various areas of public relations and give depth to understanding public relations and organization-stakeholder dynamics. RET is a future-oriented theory that gives insight into how expectations form and what components need to be analyzed to evaluate their future direction.

\section{Expectations in public relations}

Expectations appear across many areas of academic research on public relations. Expectations can be mentioned, for example, as one of the factors that organizations should try to identify and monitor to keep abreast or ahead of changes in their environment, along with attitudes, values, and norms (Heath and Bowen 2002; Ledingham 2003). The concept is likely to be familiar to scholars of issues management, as expectations can result in urgent issues when left unanswered (e.g., Jaques 2009; Reichart 2003). Scholars of relationship management may refer to expectations as the makings of the "relationship history" between an organization and its stakeholders, which is shaped by met and unmet expectations (Coombs 2000), or as factors that can induce changes in relationships or even cause relationships to end (Coombs 2000; Ledingham 2003). For scholars of reputation management, expectations can unfold as assessments of organizational ability (e.g., Eisenegger 2009). Mismatched or misinterpreted expectations also can appear in crisis management literature, this time as potential causes of crises (Brønn 2012; Coombs 2000). 
In a systematic review of several decades of public relations literature (Olkkonen \& Luoma-aho 2015), expectations were connected to the following seven concepts: reputation, responsibility, relationship, legitimacy, satisfaction, trust, and identity. Next, we elaborate on each of them. When expectations are used to explain reputations, an organization's reputation is defined as the ability or capacity to fulfill the expectations posed by stakeholders or publics or as an assessment of how well the organization is meeting expectations (e.g., Coombs 2007; de QuevedoPuente, de la Fuente-Sabaté, and Delgado-García 2007; Westhues and Einwiller 2006). Furthermore, exceeding expectations can be seen as a way to strengthen or improve reputation; whereas, failing to meet expectations can be seen as a source for reputational threats (e.g., Brønn 2012; de Quevedo-Puente de la Fuente-Sabaté, and Delgado 2007). Responsibility can be explained as conformance to societal expectations or as anticipation of societal expectations (e.g., Golob, Jancic, and Lah 2009; Westhues and Einwiller 2006), much in the same vein as legitimacy, which can be defined as societal support for organizational actions that result from congruence with societal expectations and norms (e.g., Barnett 2007; Johansen \& Nielsen 2012).

In terms of organization-stakeholder relations, expectations are mentioned as factors that starts relationships (Broom, Casey and Richey 1997), as well as factors that affect relationships after they are formed; for example, in the sense that relationships include an interchange of needs, expectations, and fulfillment (Ledingham 2003). Furthermore, relationship management can be treated as a tool for aligning or reconciling organizational behavior with the expectations of stakeholders or publics (e.g., Bruning and Galloway 2003). In relation to satisfaction, expectations are factors that contribute to why relationships end, particularly as dissatisfaction can result from unfulfilled expectations (e.g., Jo 2006; Ledingham, Bruning, and Wilson 1999). In addition to 
satisfaction in relationships, expectations are connected to satisfaction attached to products and services (e.g., Brønn 2012).

Expectations are further connected to stakeholder trust in the sense that trust can be seen as reinforcing future positive expectations and generating a feeling of satisfaction; that is, a feeling that expectations and experiences meet (e.g., Kramer 2010). Trust can be seen as a willingness to rely on another based on a positive expectation (e.g., Poppo and Schepker 2010). Finally, research that connects expectations with identity call for congruence between organizational identity and expectations; mismatches between expectations and organizational conduct are seen as future threats for identity (e.g., Illia et al. 2004).

The examples above show how many areas of research expectations touch upon in the public relations literature. As a whole, the connections to issues management, relationship management, reputation management, crisis management, and to the concepts of reputation, responsibility, relationship, legitimacy, satisfaction, trust, and identity, give hints regarding what areas of public relations could possibly be understood better by clarifying expectations at a theoretical and conceptual level in the academic research. Expectations are an intersecting phenomenon in public relations because they not only explain individual areas and concepts, but they also often interlink two or more concepts; for example, expectations of responsibility can be connected to how reputations are assessed (e.g., Berens and van Riel 2004; Ponzi, Fombrun, and Gardberg 2011).

Despite the way expectations intersect important areas of public relations research and practice, expectations are mainly used to explain other concepts and, perhaps, for this reason, expectations' role in existing research is often cursory. From this perspective, it is not surprising 
that public relations scholars seldom use or develop theoretical models for addressing expectations. Thus, we now turn our attention to making (theoretical) sense of expectations' role in one of the broadest areas of the field: relationships.

\section{Theory on expectations in relationships}

There is wide agreement that the specific focus on relationships between organizations and their publics is the defining factor that sets public relations apart from other fields (e.g., Botan \& Taylor 2004), even to the extent that relationship management could serve as a general theory of public relations (Ledingham 2003). While more factors affect relationships than expectations (e.g., Thomlison 2000), we dedicate this section to explaining expectations' relevance to relationships. Moreover, we step outside the scope of existing public relations research in our search for a more solid theoretical foundation for expectations. This is done by discussing different theoretical perspectives that place expectations in relationships: we present theories and models that relate to different phases of relationships and their formation, starting from relationship entry, moving on to interaction in relationships, and finally to relationship outcomes and continuation. Table 1 presents an overview of the theories and models discussed in this section. We present each theory or model briefly; the aim is not to discuss the theories exhaustively or to present a comprehensive list of theories, but rather to demonstrate expectations' theoretical relevance for relationships. 
Table 1. Theories that place expectations in relationships

\begin{tabular}{lll}
\hline Relationship stage & Theories contributing & $\begin{array}{l}\text { Brief description of how } \\
\text { expectations are addressed }\end{array}$
\end{tabular}

\begin{tabular}{|c|c|c|}
\hline \multirow[t]{2}{*}{ ENTRY } & $\begin{array}{l}\text { Social exchange theory } \\
\text { (Homans 1961; Blau 1964) }\end{array}$ & $\begin{array}{l}\text { Decision to engage in a } \\
\text { relationship is influenced by an } \\
\text { evaluation of the expected costs } \\
\text { and rewards. }\end{array}$ \\
\hline & $\begin{array}{l}\text { Expectancy value theory } \\
\text { (Atkinson 1957) }\end{array}$ & $\begin{array}{l}\text { Motivation is an interplay between } \\
\text { what is considered valuable and } \\
\text { whether the outcome can be } \\
\text { achieved. }\end{array}$ \\
\hline \multirow[t]{2}{*}{ INTERACTION } & $\begin{array}{l}\text { Symbolic interaction } \\
\text { (Blumer 1969) }\end{array}$ & $\begin{array}{l}\text { Meanings, roles, and cues that are } \\
\text { given in an interaction invoke } \\
\text { expectations of others' and own } \\
\text { behavior. }\end{array}$ \\
\hline & $\begin{array}{l}\text { Expectation states theory } \\
\text { (Berger \& Zelditch 1998) }\end{array}$ & $\begin{array}{l}\text { Assessments and anticipations of } \\
\text { others lead to performance } \\
\text { expectations that shape hierarchy } \\
\text { and behavior. }\end{array}$ \\
\hline \multirow[t]{3}{*}{$\begin{array}{l}\text { OUTCOME; } \\
\text { CONTINUATION }\end{array}$} & $\begin{array}{l}\text { Expectancy disconfirmation theory } \\
\text { (Oliver 1980) }\end{array}$ & $\begin{array}{l}\text { Satisfaction depends on a } \\
\text { comparison or an assessment that } \\
\text { is made based on how well the } \\
\text { initial expectations were met. }\end{array}$ \\
\hline & $\begin{array}{l}\text { The gap model } \\
\text { (Zeithaml, Parasuraman and Berry } \\
\text { 1990) }\end{array}$ & $\begin{array}{l}\text { Discrepancies between initial } \\
\text { expectations and perceived } \\
\text { performance explain how } \\
\text { (dis)satisfaction occurs. }\end{array}$ \\
\hline & $\begin{array}{l}\text { Expectancy violations theory } \\
\text { (Burgoon 1993) }\end{array}$ & $\begin{array}{l}\text { Emotional experience and } \\
\text { expression can be explained with } \\
\text { positively or negatively confirmed } \\
\text { or violated expectations. }\end{array}$ \\
\hline
\end{tabular}

\subsection{Relationship entry: Social exchange theory and expectancy value theory}

The decision to engage in a relationship is an assessment process in which relational partners assess possible outcomes, the requirements the relationship puts on them, and how motivated they are to 
interact. These dynamics are explained by the social exchange theory (Homans 1961; Blau 1964) and the expectancy-value theory (Atkinson 1957; Wigfield and Eccles 2000) from social and educational psychology.

Social exchange theory (Homans 1961; Blau 1964) is a major theoretical perspective in social psychology that explains the social behavior and interaction of relational partners as reciprocal or negotiated exchanges (Cook and Rice 2013). Essentially, the social exchange theory takes interest in the intangible or intangible "exchange" between relational partners that is understood to depend on an assessment of expected costs and rewards (Cook and Rice 2013). The theory rests on assumptions that actors engage with others when they have a desired goal they want to obtain. When actors engage with others, there are always some costs, and choosing to engage depends on weighing the expected costs with the possible rewards (Blau 1964). Rewards can be understood in different ways, depending on what the actor finds as valuable. For example, acceptance, approval, respect, prestige, compliance, or power are examples of social rewards (Blau 1964: 100). Equally, costs can take many forms, starting from investment of time and effort, to material resources, and opportunities that are lost while engaging in a certain relationship (Blau 1964; Homans 1961). If the costs of interaction are expected to exceed the potential benefits and rewards, or if the expected rewards are higher in some other (competing) relationship, actors can restrain from forming a relationship in the first place. Within the domain of public relations, the social exchange theory has been applied to argue for a relational theory for public relations (Ledingham 2001), with some reference to the importance of expectations in relationships.

Expectancy-value theory (Atkinson 1957; Wigfield and Eccles 2000) suggests that the assessments made by individuals are influenced by what is considered valuable and whether they 
think they can achieve that outcome. Expectancy-value theory relates strongly to motivation both in terms of motivation to succeed and motivation to avoid failure (Wigfield, Tonks, and Klauda 2009). Although one of the main domains for the expectancy-value theory is educational psychology, the theory also includes applications to, for example, the broad area of work motivation (e.g., Van Eerde and Thierry 1996). Recently, the expectancy-value theory has also been connected to stakeholder participation (Purvis, Zagenczyk, and McCray 2015), which brings the theory closer to an organization's relationships with its central stakeholders and publics. In their study of stakeholder participation, Purvis, Zagenczyk, and McCray (2015) suggested that expectations influence whether stakeholders are motivated to participate in a project, and whether they will help or harm the completion of the project. Within public relations research, the expectancy-value theory has been applied to explain, for example, preferences for corporate responsibility practices (David, Kline, and Dai 2005), yet without specifically focusing the study on expectations. As we see it, the value of the expectancy-value theory to public relations is that it explains how individuals assess what they can achieve by engaging in something, and how the expectations they make based on this assessment further impact their motivation in a relationship.

\subsection{Relationship interaction: Symbolic interactionism and expectation states theory}

Once the relationship has begun, the relational partners organize their interaction, roles, and dynamics. This phase of relationship development is explained by symbolic interactionism (Blumer 1969) and expectation states theory (Berger and Zelditch 1998).

Symbolic interactionism (Blumer 1969) explains society as "a web of communication or interaction, the reciprocal influence of persons taking each other into account as they act" (Stryker \& Vryan 2006: 3). The word "symbolic" refers to the meanings, roles, and cues developed while 
interacting with another-interacting is not only about reacting to each other's actions, but about interpreting and defining those actions (Blumer 1969). Stryker and Vryan (2006) explain the role of expectations in symbolic interactionism as follows:

Interacting persons recognize and label one another as occupants of positions, invoking linked expectations. They label themselves, invoking expectations for their own behavior. On entering situations, people define who they and others in the situation are and what the situation itself is, and they use these definitions to organize their behavior. Interaction can validate these definitions; it can also challenge them. Interactions are often venues for bargaining or conflict over alternative definitions, for battles over whose definitions will hold and organize the interaction. (Stryker \& Vryan 2006: 23)

In the context of public relations, Hallahan (1999) has discussed symbolic interactionism in connection to framing and persuasion. He mentions expectations as factors affecting not only how frames are interpreted, but also as products of framing — a certain type of framing can create certain expectations (Hallahan 1999).

Expectation states theory originates from observations about differences in participation, evaluation, and influence across members of (small) groups, and how status hierarchies that stem from differences in prestige and power can explain them (Berger and Zelditch 1998; Correll and Ridgeway 2006). As Correll and Ridgeway (2006) describe, expectation states theory explains how members in groups with a collective task or a goal make assessments and anticipations of other members of the group, leading to performance expectations that, once developed, shape the group's hierarchy and behavior in a self-fulfilling manner (Correll and Ridgeway 2006: 31). Expectation states theory relates mostly to group dynamics, and how some members are given 
more chances to speak, suggest, and decide — often implicitly and unconsciously — while others are given fewer opportunities. As organizations and their stakeholders or publics are not taskoriented groups as such, the relevance of expectation states theory for public relations is limited. However, task orientation can gain relevance when organizations seek collective action and engagement with their stakeholders and publics. Thus, we see value in how expectation states theory recognizes status characteristics, such as background and expertise, as antecedents for expectations on interaction, how input is valued, and how others are heard in the process (cf. Correll and Ridgeway 2006).

Overall, theories that explain expectations in relationship interaction become relevant especially from the perspective of stakeholder categorizations and how different voices are heard. Furthermore, these theories can have relevance for stakeholder engagement and collaboration, as the theories are about assessing the relational partner's behavior and characteristics.

\subsection{Relationship outcomes and continuation: Expectancy disconfirmation theory, the gap model, and expectancy violations theory}

Once the relationship is underway, the actors engaged in it assess whether the relationship is meeting their expectations. These confirmations and discrepancies have been addressed by both the expectancy disconfirmation theory (Oliver 1980) and the gap model (Zeithaml, Parasuraman, and Berry 1990) in customer satisfaction literature, and by expectancy violations theory (Burgoon 1993) in interpersonal communication.

Expectancy disconfirmation theory explains how customer satisfaction depends on a comparison or an assessment of a product or a service based on how well the initial expectations 
were met (Oliver 1980). Disconfirmation refers to "a subjective post-usage comparison" (Lankton and Mcknight 2012: 89). A similar argument is posed by the gap model that explains dissatisfaction as discrepancy (i.e., a gap) between initial expectations and perceived performance (Zeithaml, Parasuraman, and Berry 1990). Expectation gaps can originate from multiple sources: not knowing what is expected, offering a quality that does not meet expectations, not meeting expectations with performance, or promising something that cannot be delivered (Zeithaml, Parasuraman, and Berry 1990). In the field of public relations, Brønn (2012) has used the gap model in connection with corporate responsibility communication, reputation management, and risk management - with considerable attention given to expectations and how their violations potentially hurt organizations.

According to expectancy violations theory, expectations can be either confirmed or violated - positively or negatively. In the case of positive violation, the enacted behavior is more positive than initially expected, and, in the case of negative violation, the enacted behavior is more negative than initially expected (Burgoon 1993). The theory poses that these violations explain emotional experience and expression in relationships. For example, a violation of expectations can distract attention from the original situation or issue, as the violation leads to emotional responses and a need to make sense of the violation, as well as to evaluate its consequences (Burgoon 1993). In public relations research, expectancy violations theory has been applied to predict how publics react to organizations' attempts to mimic interpersonal communication on social media (Sung and Kim 2014).

To sum up the reviewed theories relating to relationship outcomes and continuation, the expectations formulated in the beginning of the relationship affect how the relationship is 
evaluated and whether it is perceived as worth continuing. Fulfilling positive expectations, for example, by delivering good quality and keeping promises, generally leads to positive assessments of the relationship. When gaps or violations occur, they can pose threats to the continuation of the relationship.

$* * *$

We conclude by noting how expectations connect to relationships in different contexts such as social groups, work, customer relations and interpersonal communication. For the most part, these micro-level theories explain interpersonal relationships; however, some examples illustrating how these theories apply in context of public relations exist. Therefore, while theoretical understanding of expectations is making its way into public relations research, we propose there is a further need to theorize how expectations play out specifically in organization-stakeholder relations. Thus, we move on to discuss the concept of expectations.

\section{Defining expectations}

Concepts are the building blocks in theory construction (Walker and Avant 2011; Gioia, Corley, and Hamilton 2013); therefore, we continue our theoretical endeavor from the conceptual level of defining expectations. Considering how often and how widely expectations are connected to public relations, existing literature gives us surprisingly few actual definitions of expectations in public relations (Olkkonen 2017; Olkkonen 2015a; Olkkonen and Luoma-aho 2015). Often, the role of expectations is cursory in that it explains other concepts and relations between concepts; for example, that meeting expectations of corporate responsibility is crucial for maintaining reputations and legitimacy (Olkkonen 2017). Therefore, to offer a solid foundation for building 
theory on expectations in public relations, we take another step outside the scope of public relations, this time by reviewing literature on customer management and customer satisfaction, which are areas with detailed conceptual insight on expectations and illustrative introductions to the positive and negative elements of expectations.

Customer management and customer satisfaction research offers not one but several definitions to understand the full range of expectations. Using this background, expectations can be seen as a dynamic phenomenon where different factors can affect the final formation of an expectation (see, e.g., Miller 1977; Summers and Granbois 1977; Swan, Trawick, and Carroll 1982; Woodruff, Cadotte, and Jenkins 1983; Zeithaml, Berry, and Parasuraman 1993; also Olkkonen and Luoma-aho 2015). These factors have been suggested to create different expectation types that have different origins (Summers and Granbois 1977; Woodruff, Cadotte, and Jenkins 1983). The types suggested are abundant, some dealing with values, such as "normative" (Summers and Granbois 1977) or "ideal" expectations (Miller 1977), while some rest on the information that is available, such as "precise" or "realistic" expectations (Ojasalo 2001). Furthermore, previous experience is recognized as a factor for expectation formation, for example, in "experience-based" expectations (Woodruff, Cadotte, and Jenkins 1983). Finally, expectations can be driven by personal interest as suggested in "deserved" (Miller 1977) or "desired" expectations (Swan, Trawick, and Carroll 1982).

Based on an extensive review of customer management and customer satisfaction literature (Olkkonen and Luoma-aho 2015), we have previously categorized expectations into four streams that explain the range of different expectation types:

1. Value-based expectations (Miller 1977; Summers and Granbois 1977): Normative 
expectations that indicate an ideal state based on what is valued or wished for. Value-based expectations are the most difficult to fulfill due to their idealistic and sometimes unrealistic nature. Also referred to as "ideal" or "should" expectations.

2. Information-based expectations (Miller 1977; Ojasalo 2001): Expectations based on what is known and what information is available or unavailable. Information-based expectations can be influenced by both explicit facts and implicit cues. Moreover, information-based expectations may become unrealistic or fuzzy based on imprecise or lack of information. Also referred to as "precise," "realistic," "explicit," and "official" expectations.

3. Experience-based expectations (Miller 1977; Summers and Granbois 1977; Swan, Trawick, and Carroll 1982; Woodruff, Cadotte, and Jenkins 1983; Zeithaml, Berry, and Parasuraman 1993): Expectations based on direct or indirect previous experiences that guide what is believed to be possible. Experience-based expectations indicate a likelihood similar to predictive expectations, or they result from comparisons with similar brands or organizations. Prior experiences can raise or lower these expectations to avoid future disappointments. Also referred to as "brand-based," "comparative," or "minimum tolerance" expectations.

4. Personal interest-based expectations (Miller 1977; Swan, Trawick, and Carroll 1982; Zeithaml, Berry, and Parasuraman 1993): Expectations that are primarily influenced by personal evaluations of gains and assessments of what is deserved, based on desires, or the effort and resources invested. These expectations are a challenge for brands and organizations as they can cause some information to be filtered out when it does not match personal interests. Also referred to as "desired," "deserved," or "unofficial" expectations. 
Each of the four categories gives different conceptual explanations to expectations. These categories add to the previous understanding of public relations literature not only by explaining the many ways expectations form, but also by drawing attention to how the assessment of fulfilled or violated expectations is actually very different depending on the expectation type. Most importantly, while value- and interest-based expectations are, presumably, always positive hopes, wishes, or demands as they are based on what should or ought to be, information- and experiencebased expectations can take both positive and negative forms. For example, if prior experience has been a disappointment, an expectation based on probability might predict the disappointment to repeat itself. This connects not only to how not meeting positive expectations can lead to reputational losses, but how meeting negative expectations might actively build or maintain an unfavorable reputation or, for example, cause damage to legitimacy. Moreover, when understood as negative anticipations, expectations can help to decipher why stakeholders and publics sometimes display pessimism or cynicism toward organizations. We suggest that understanding the different expectation types and, furthermore, understanding expectations as positive and negative, as well as normative and predictive constructs explains more profoundly how they influence public relations.

The conceptual understanding of expectations, in addition to what we have presented in the previous sections, sets the stage for formulating our own theorization of expectations in the specific context of public relations. The next section articulates the postulations for this theorization. 


\section{Relationship Expectation Theory (RET)}

So far, we have discussed theories and models that address expectations in relationships, and articulated the different ways expectations are understood at a conceptual level. Our earlier work suggested that organizations can make sense of expectations by analyzing the outcomes the stakeholders or publics value and the confidence they place in an organization (see the Expectation Grid first introduced by Olkkonen and Luoma-aho 2015; empirically tested and revised by Olkkonen 2015a, 2015b, see also Olkkonen 2017). We draw on this background but take a step forward by elaborating on what we mean with an interplay between valued outcomes (normative assessment) and confidence placed on an organization (organization-specific assessment). We draw from the previous sections to build three postulations for our theory to explain expectations in public relations: the Relationship Expectation Theory.

Social exchange theory and expectancy value theory connect with value- and interest-based expectation types, as these theories explain how the prospect of valuable outcomes and rewards affect relationships, especially in their formation stage. Although social exchange theory and expectancy value theory are mainly micro level theories, we assume that expectation formation is universal for all relationships where humans are involved (cf. Thomlison 2000). Therefore, values and interests represent the outcomes that stakeholders and publics are looking for in a relationship and, vice versa, are seeking to avoid. Based on this, we formulate the first postulation for theorizing expectations in public relations:

Postulation 1: Stakeholders and publics assess desirable and undesirable outcomes when they form expectations for organizations, and these assessments are influenced by values and interest. 
Values and interests are relatively static in that they remain the same when stakeholders and publics assess different organizations; thus, they are the baseline for forming expectations. As we have argued elsewhere (Olkkonen 2015a; Olkkonen and Luoma-aho 2015), value- and interestbased expectations guide the normative assessment of expectation formation, and they vary depending on what is desirable and why_-bound both by individual and cultural variance. Hence, values can, for example, range from economic to societal values, and interests can be anything from very limited self-interest to utilitarianism. We also argue that organizations can influence value- and interest-based expectations only to a limited extent, for example, by taking part in the discussions that shape societal values and trends. In essence, our first postulation implies that both positive and negative outcomes are assessed when stakeholders and publics form expectations for organizations.

When we examine expectations beyond their normative dimension, we can again refer to social exchange theory and expectancy value theory in how they explain the impact of expected costs and probabilities on relationships. Similarly, in symbolic interaction and expectation states theory relationships are affected by how we judge and anticipate others' behavior and characteristics. Expectancy disconfirmation theory, the gap model, and expectancy violations theory are also relevant as they explain how relationship outcomes are assessed based on whether expectations prove to be true. In terms of expectation types, information and experience-based expectations deal mostly with this predictive side of expectation formation. Based on these arguments, our next postulation is: 
Postulation 2: When expectations are attached to specific organizations, stakeholders' and publics' values and interests are weighed against experience and information about an organization's ability and willingness to deliver preferred outcomes.

As predictive expectations derive mostly from experience and available (direct or indirect) information, organizations have more direct influence over them, for example, if their communication matches the actual actions that the organization takes. This is what we have described earlier as the organization-specific assessment, which is actually embedded in the normative assessment as it takes a reference point in values and interests (Olkkonen 2015a; Olkkonen and Luoma-aho 2015). However, compared to the normative assessment, the organization-specific assessment is more dynamic and predictive: it is close to the actual target of expectations and describes how likely it is to attain preferred outcomes in the case of a specific organization. Essentially, the organization-specific assessment can result in positive or negative expectations, as the stakeholders assess how likely it is that their expectations will be fulfilled; that is, how willing and able the organization is perceived to meet their values and interests. The organization-specific assessment can turn an expectation negative if the organization is perceived as unwilling or unable to either offer an outcome that is valued, or to prevent an outcome that is not valued. Hence, the importance of our second postulation is that stakeholders and publics can form both positive and negative expectations for organizations and their conduct.

The two embedded assessments-normative assessment of different outcomes and organization-specific assessment dealing with confidence in a particular organization-make expectations "positive or negative future-oriented assessments of an organization's ability and willingness that form in the interplay between normative and predictive factors" (Olkkonen 2015a: 
60). In other words, expectations form an interplay between the outcomes the stakeholders and publics value and the confidence they place on an organization. What we pause to argue here is that expectations are not to be treated too lightly in academic research of public relations, as they are a complex phenomenon with significant implications for relationships. Their complex nature holds whether we talk about establishing relationships, interacting in them, or judging when they are satisfying and worth continuing. Thus, we push for a need to articulate a theory for expectations in public relations that inevitably includes interplay between preferred outcomes (values and interests) and confidence in a particular organization (influenced by information and experience). This leads us to the third and final postulation for RET:

Postulation 3: The interplay between normative and organization-specific assessments results in positive and negative expectations attached to organizations.

Our interpretation of the different expectation types, based on both conceptual and empirical work (Luoma-aho and Olkkonen 2016; Olkkonen 2015a, 2015b, 2017; Olkkonen and Luoma-aho 2015) is that the normative and (organization-specific) predictive interplay can lead to optimistic, hopeful, cynical, or pessimistic expectations. We next elaborate on each by following Figure 1, a visualization of how we draw together our three postulations to formulate the Relationships Expectation Theory (RET) for public relations. 


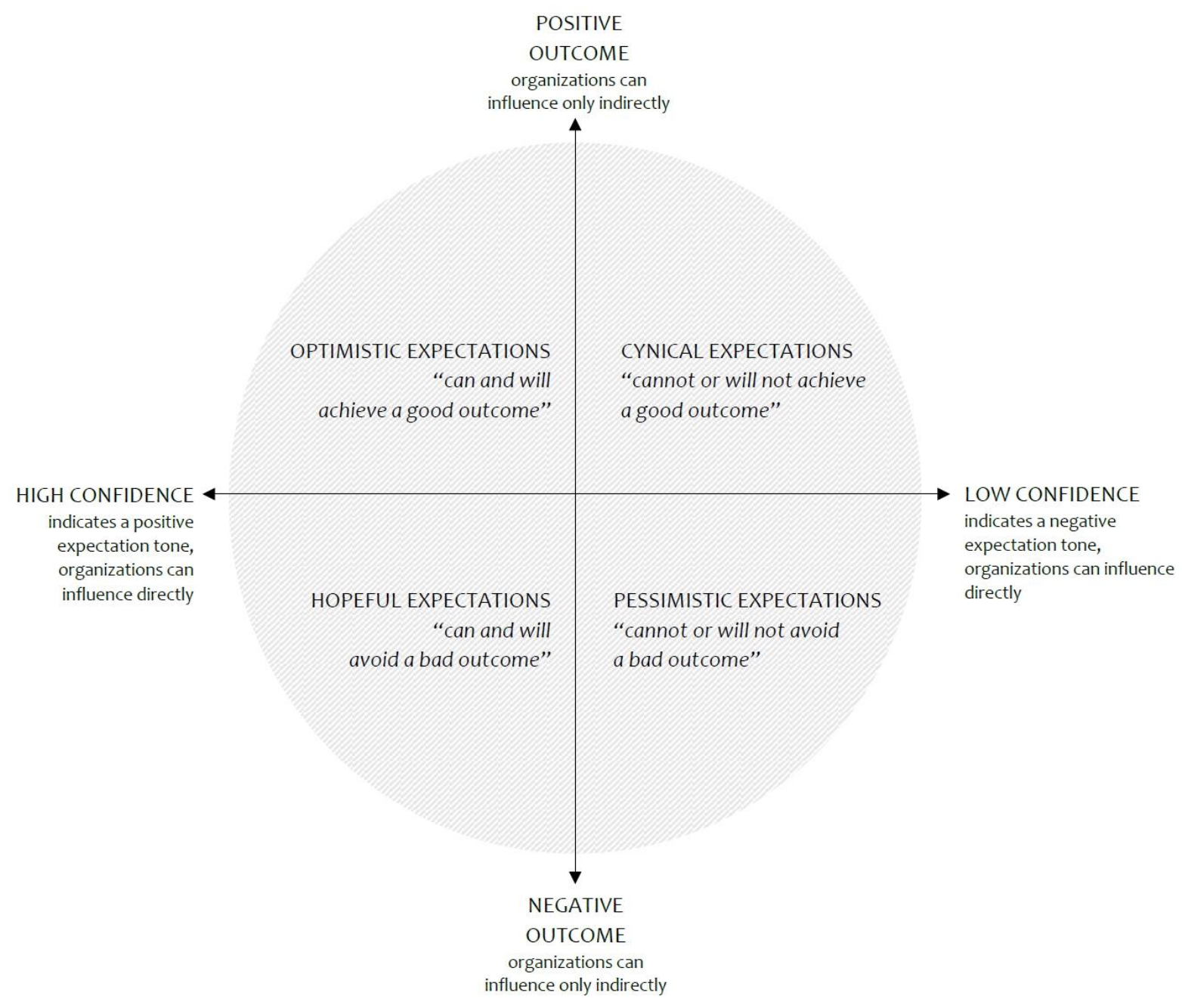

Figure 1. Relationship Expectation Theory (RET) for public relations (adapted from Olkkonen and Luoma-aho 2015)

The two axes of Figure 1 are based on the first two postulations: the vertical axis portrays the assessment of outcomes, which can be viewed positively or negatively by stakeholders and publics, and the horizontal axis represents stakeholders' or publics' assessments of whether and organization is perceived able and willing to deliver the outcomes. As a result, organizations may 
face two types of positive and two types of negative expectations. As illustrated in the figure, RET acknowledges two types of positive expectations: optimistic and hopeful. When stakeholders or publics have optimistic expectations, they anticipate that the organization is willing and able to offer outcomes they value. This is perhaps most easily visible in communicating values, mission, and organizational purpose; when these meet with stakeholder values and interests, expectations are optimistic. The other positive expectation type is hopeful, which indicates an anticipation that the organization is willing and able to prevent an outcome the stakeholder or public perceives as negative. This could be, for example, an organization's good reputation in tackling social challenges or maintaining high environmental standards despite possible risks. The difference between these two is the outcome that is assessed. An optimistic expectation is connected to a positive outcome (and its delivery); whereas a hopeful expectation is connected to a negative outcome (and its prevention). Overall, positive expectations are a sign of confidence and trust in the organization; hence, their violation is also likely to violate the confidence and trust invested in them.

Figure 1 further presents two negative expectations: cynical and pessimistic. When expectations are negative, confidence in the organization's willingness and ability is low. Cynical expectations indicate an anticipation that the organization is unwilling or unable to offer outcomes that stakeholders and publics perceive as positive. This could be the result of, for example, greenwashing, lip service or window-dressing that leave stakeholders dissatisfied and expecting further disappointments. A pessimistic expectation indicates an anticipation that the organization is unwilling or unable to prevent an outcome that the stakeholder perceives as negative. An example of a pessimistic expectation could relate to, for example, discrimination, pollution, or privacy. The difference between cynical and pessimistic expectations again is the outcome. 
As the vertical axis shows, our formulation of RET acknowledges that organizations can influence expectations only to a limited extent, especially in relation to the normative assessment guided by values and interests. Organizations' influence over the information and experiences that shape expectations is more direct and they can, for example, attempt to frame their communication, seek for a fit between what is done and what is communicated, and find ways to include and engage their stakeholders in their actions. However, the line between direct and indirect influence is not clear-cut, as even every information-based and experience-based expectation takes a comparison point in the value-based and interest-based expectations.

The added value of Relationship Expectation Theory when compared to existing theoretical knowledge of expectations in public relations is that it 1) takes into account that expectations are multi-dimensional rather than one-dimensional constructs, 2) connects the understanding of expectations to the context of a specific organization and the confidence invested in it, and 3) recognizes that organizations can influence expectations only to a limited extent.

If we were to apply expectation mapping and analysis to the function of public relations, overlapping areas could include relationship management, including monitoring and listening. Furthermore, mapping and analyzing expectations could take on a more strategic role in public relations, relating to priming expectations to a realistic level, framing communication to make it meaningful, and ensuring satisfaction with sufficient disclosure and dialogue (cf. Luoma-aho, Canel \& Olkkonen 2020). Earlier, we have suggested comprehensive strategic monitoring, mapping, and analysis of stakeholder expectations as activities of expectation management that we describe as an organization's ability to manage its own understanding of what is expected of it, especially in terms of different expectation types and their differences in relevance and priority 
(Luoma-aho and Olkkonen 2016; Olkkonen and Luoma-aho 2015; Olkkonen and Luoma-aho 2014; Olkkonen 2015a). Although management can refer to control, which consequently can raise critical questions for the (hidden) intentions of expectation analysis, we argue that in the current communication environment it is impossible to manipulate or control stakeholder or publics expectations. However, we acknowledge the ambiguity and pitfalls of the term, which calls for a need for further discussion on what organizations ideally should "do" with their knowledge of expectations. Whether we call it management, analysis, or mapping, RET gives structure to organizations' understanding of expectations.

The next section concludes our exploration of expectations and discusses the relevance of RET for the future of public relations research.

\section{Concluding remarks}

Relationships are central to public relations, and expectations affect them in every stage from the beginning to the end. This chapter has reviewed theories that address expectations in relationships and discussed their relevance for public relations. Furthermore, the chapter used the different conceptual dimensions of expectations as building blocks to theorize expectations in public relations. We formulated Relationship Expectation Theory as an emerging theory of expectations in public relations that treats expectations as multidimensional constructs, connects the understanding of expectations to the context of a specific organization and the confidence invested in it, and recognizes that organizations can influence expectations only to a limited extent.

RET explains how expectations form in an interplay between the outcomes the stakeholders or publics value and the confidence they place on an organization. As such, RET rests 
on understanding of expectation formation as a two-fold assessment process of normative assessment and organization-specific assessment. We argue that our theory responds to the apparent interest of current public relations research in expectations as factors affecting reputations, corporate responsibility, relationship management, organizational legitimacy, stakeholder satisfaction, trust, organizational identity, and issues management. Importantly, the urgency of understanding expectations is likely not to diminish in the increasingly complex environment in which organizations practicing public relations are embedded: stakeholders and publics can organize unexpectedly (e.g., Aldoory and Grunig 2012); opinions and experiences can be shared visibly, effortlessly, and potentially virally (e.g., Pang, Begam Binte Abul Hassan and Chee Yang Chong 2014); and value-polarization can cause conflicts between diverging expectations (e.g.,Wettstein and Baur 2016). As a result, there are many reasons why organizations may face expectations and expectation gaps that call for urgent attention and potentially cause serious damage to organizations and their relationships with stakeholders and publics. RET offers a theoretical frame to continue exploring specifically how expectations affect organizations in a complex environment.

As to the limitations related to RET, we note that the expectations organizations face are not likely to be a homogenous cluster even within a single stakeholder group (Olkkonen 2015b). Therefore, the reality of expectation mapping is likely to be messy, as well as laborious, involving intensive analysis. As noted during the testing and revision of our earlier model (Olkkonen 2015a, 2015b), the four expectation types represent extremities, because in reality stakeholders might display caution in their expectations rather than, for example, pure optimism or cynicism. Furthermore, expectations often seem to be interconnected; the optimism or hopes in positive expectations can be overturned by the simultaneous impact of negative expectations (Olkkonen 
2015b). This can happen, if the organization's good deeds are perceived as insufficient to counteract (broader) negative trends. Moreover, expectations can change over time as relationships evolve. Therefore, our categorizations are likely to reflect passing stages, not fixed states, which calls for longitudinal studies that can capture the dynamics of evolving expectations.

RET also sets some critical considerations for the practice of public relations. We have proposed expectation management (as management of the knowledge extracted from expectations) as a possible supplementing task for public relations practice, but management can also take the form of control and manipulation. Attempts to control, manipulate, or artificially create and steer expectations could become another suspicious and potentially unethical area that the field has been accused of containing (e.g., L'Etang 2006; L'Etang, et al. 2016). On the other hand, it can be questioned to what extent organizations have actual possibilities and power to shape expectations, especially as the normative assessment is influenced by values and interests. Relating to power, a relevant question is: Who gets to voice their expectations and to whose expectations should organizations respond? These are some of the potential critical questions for future research.

Based on what we have presented in this chapter, expectations are an emerging and intersecting theme in public relations, and one that is likely to increase in importance. Public relations as a practice is increasingly interested in predicting stakeholders' and publics' mindsets, values, and preferences to be able to safeguard their reputations, to prevent communication from backfiring and to work with stakeholders to achieve shared goals. Moreover, recent developments such as algorithms and big data give organizations increasing opportunities to monitor their audiences. A thorough understanding of expectations can give public relations research and practice predictive power in an increasingly unpredictable world of interlinked relations, networks, 
and shifting power relations. Thus, we argue that Relationship Expectation Theory is a step toward understanding the future of public relations, especially when stakeholders and publics are seen as cocreators of relationships, meaning, and communication.

\section{References}

Aldoory, Linda, \& James E. Grunig. 2012. The rise and fall of hot-issue publics: Relationships that develop from media coverage of events and crises. International Journal of Strategic Communication, 6(1), 93-108.

Atkinson, John William. 1957. Motivational determinants of risk taking behavior. Psychological Review, 64: 359-372.

Barnett, Michael L. 2007. Tarred and untarred by the same brush: Exploring interdependence in the volatility of stock returns. Corporate Reputation Review 10(1). 3-21.

Berger, Joseph \& Morris Zelditch, Jr. 1998. Status, power, and legitimacy: Strategies and theories. New Brunswick, NJ: Transaction

Berens, Guido \& Cees B. M. van Riel. 2004. Corporate associations in the academic literature: Three main streams of thought in the reputation measurement literature. Corporate Reputation Review 7(2). 161-178.

Blau, Peter Michael. 1964. Exchange and power in social life. New York: John Wiley. 
Blumer, Herbert. 1969. Symbolic Interactionism: Perspective and Method. Englewood Cliffs, NJ: Prentice-Hall.

Botan, Carl H., \& Maureen Taylor. 2004. Public relations: State of the field. Journal of Communication 54(4). 645-661.

Broom, Glen M., Shawna Casey \& James Richey. 1997. Toward a concept and theory of organization-public relationships. Journal of Public Relations Research 9(2). 83-98.

Bruning, Stephen D. \& Tara Galloway. 2003. Expanding the organization-public relationship scale: Exploring the role that structural and personal commitment play in organizationpublic relationships. Public Relations Review 29(3). 309-319.

Brønn, Peggy Simcic. 2012. Adapting the PZB service quality model to reputation risk analysis and the implications for CSR communication. Journal of Communication Management 16(1). $77-91$.

Burgoon, Judee K. 1993. Interpersonal expectations, expectancy violations, and emotional communication. Journal of Language and Social Psychology 12(1-2). 30-48.

Coombs, W. Timothy. 2000. Crisis management: Advantages of a relational perspective. In John A. Ledingham \& Stephen D. Bruning (eds.), Public Relations as Relationship Management, 73-93. Mahwah, NJ: Lawrence Erlbaum Associates.

Coombs, W. Timothy. 2007. Protecting organization reputations during a crisis: The development and application of situational crisis communication theory. Corporate Reputation Review 10(3), 163-176. 
Cook, Karen S. \& Eric Rice. 2013. Social exchange theory. In John DeLamater \& Amanda Ward (eds.) Handbook of Social Psychology, $2^{\text {nd }}$ edition, 61-88. Dordrecht: Springer.

Correll, Shelley. J. \& Cecilia. L. Ridgeway. 2006. Expectation states theory. In John Delamater (ed.) Handbook of social psychology, 29-52. New York: Springer.

David, Prabu, Susan Kline, and Yang Dai. 2005. Corporate social responsibility practices, corporate identity, and purchase intention: A dual-process model. Journal of Public Relations Research 17(3). 291-313.

de Quevedo-Puente, Esther, Juan Manuel de la Fuente-Sabaté \& Juan Bautista Delgado-García. 2007. Corporate social performance and corporate reputation: Two interwoven perspectives. Corporate Reputation Review 10(1). 60-72.

Eisenegger, Mark. 2009. Trust and reputation in the age of globalization. In Joachim Klewes \& Robert Wreschniok (eds.) Reputation Capital, 11-22. Berlin: Springer.

Fombrun, Charles J. \& Rindova, Violina. 1998. Reputation management in global 1000 firms: A benchmarking study. Corporate Reputation Review 1(3). 205-212.

Gioia, Dennis A., Kevin G. Corley \& Aimee L. Hamilton. 2013. Seeking qualitative rigor in inductive research: Notes on the Gioia methodology. Organizational Research Methods 16(1). 15-31.

Global Alliance for Public Relations and Communication Management. 2012. The Melbourne Mandate. A Call to Action for New Areas of Value in Public Relations and Communication Management. 
Golob, Urša, Zlatko Jancic \& Borut Marko Lah. 2009. Corporate social responsibility and transparent pricing in the case of the euro changeover. Corporate Communications: An International Journal 14(4). 456-469.

Hallahan, Kirk. 1999. Seven models of framing: Implications for public relations. Journal of Public Relations Research 11(3). 205-242.

Heath, Robert L. \& Shannon A. Bowen. 2002. The public relations philosophy of John W. Hill: Bricks in the foundation of issues management. Journal of Public Affairs 2(4). 230-246.

Homans, George Caspar. 1961. Social behavior: Its elementary forms. New York: Harcourt Brace.

Illia, Laura, Evelyn Schmid, Irene Fischbach, Robert Hangartner \& Roberto Rivola. 2004. An issues management perspective on corporate identity: The case of a regulatory agency. Corporate Reputation Review 7(1). 10-21.

Jaques, Tony. 2009. Issues and crisis management: Quicksand in the definitional landscape. Public Relations Review 35(3). 280-286.

Jo, Samsup. 2006. Measurement of organization-public relationships: Validation of measurement using a manufacturer-retailer relationship. Journal of Public Relations Research 18(3). $225-248$.

Johansen, Trine Susanne \& Anne Ellerup Nielsen. 2012. CSR in corporate self-storying: Legitimacy as a question of differentiation and conformity. Corporate Communications: An International Journal 17(4). 434-448. 
Kramer, Roderick M. 2010. Collective trust within organizations: Conceptual foundations and empirical insights. Corporate Reputation Review 13(2). 82-97.

Lankton, Nancy K., \& D. Harrison McKnight. 2012. Examining two expectation disconfirmation theory models: assimilation and asymmetry effects. Journal of the Association for Information Systems 13(2). 88-115.

Ledingham, John A. 2001. Government-community relationships: Extending the relational theory of public relations. Public Relations Review 27(3). 285-295.

Ledingham, John A. 2003. Explicating relationship management as a general theory of public relations. Journal of Public Relations Research 15(2). 181-198.

Ledingham, John A., Stephen D. Bruning \& Laurie J. Wilson. 1999. Time as an indicator of the perceptions and behavior of members of a key public: Monitoring and predicting organization-public relationships. Journal of Public Relations Research 11(2). 167-183.

Luoma-aho, Vilma, María-José Canel \& Laura Olkkonen. 2020. Public sector communication and citizen expectations and satisfaction. In Vilma Luoma-aho \& María-José Canel (Eds.) Handbook of Public Sector Communication. New York: Wiley Blackwell.

Luoma-aho, Vilma \& Laura Olkkonen. 2016. Expectation management. In C. E. Carroll (ed.), The SAGE Encyclopedia of Corporate Reputation, I:303-306. Thousand Oaks, CA: SAGE.

L'Etang, Jacquie. 2006. Public relations and propaganda: Conceptual issues, methodological problems, and public relations discourse. In Jacquie L'Etang \& Magda Pieczka (eds.). 
Public relations: Critical debates and contemporary practice, 23-40. Mahwah, NJ: Lawrence Erlbaum Associates.

L'Etang, Jacquie, David McKie, Nancy Snow \& Jordi Xifra. 2016. The Routledge handbook of critical public relations. London and New York: Routledge.

L'Etang, Jacquie \& Magda Pieczka (eds.). 2006. Public relations: Critical debates and contemporary practice. Mahwah, NJ: Lawrence Erlbaum Associates.

Miller, John A. 1977. Studying satisfaction, modifying models, eliciting expectations, posing problems, and making meaningful measurements. In $H$. Keith Hunt (ed.), Conceptualization and Measurement of Consumer Satisfaction and Dissatisfaction, 72-91. Cambridge, MA Marketing Science Institute.

Ojasalo, Jukka. 2001. Managing customer expectations in professional services. Managing Service Quality 11(3). 200-212.

Oliver, Richard L. 1980. A cognitive model of the antecedents and consequences of satisfaction decisions. Journal of Marketing Research 17. 460-469.

Olkkonen, Laura. 2015a. Stakeholder expectations: Conceptual foundations and empirical analysis. Jyväskylä: University of Jyväskylä doctoral dissertation.

Olkkonen, Laura. 2015b. Audience enabling as corporate responsibility for media organizations. Journal of Media Ethics 30(4). 268-288. 
Olkkonen, Laura. 2017. A conceptual foundation for expectations of corporate responsibility. Corporate Communications: An International Journal 22(1). 19-35.

Olkkonen, Laura \& Luoma-aho, Vilma. 2014. Public relations as expectation management? Journal of Communication Management 18(3). 222-239.

Olkkonen, Laura \& Vilma Luoma-aho. 2015. Broadening the concept of expectations in public relations. Journal of Public Relations Research 27(1). 81-99.

Pang, Augustine, Nasrath Begam Binte Abul Hassan \& Aaron Chee Yang Chong. 2014. Negotiating crisis in the social media environment: Evolution of crises online, gaining credibility offline. Corporate Communications: An International Journal, 19(1), 96-118.

Ponzi, Leonard J., Charles J. Fombrun \& Naomi A. Gardberg. 2011. RepTrak ${ }^{\mathrm{TM}}$ Pulse: Conceptualizing and validating a short-form measure of corporate reputation. Corporate Reputation Review 14(1). 15-35.

Poppo, Laura \& Donald J. Schepker. 2010. Repairing public trust in organizations. Corporate Reputation Review 13(2). 124-141.

Purvis, Russell L., Thomas J. Zagenczyk, \& Gordon E. McCray. 2015. What's in it for me? Using expectancy theory and climate to explain stakeholder participation, its direction and intensity. International Journal of Project Management 33(1). 3-14.

Reichart, Joel. 2003. A theoretical exploration of expectational gaps in the corporate issue construct. Corporate Reputation Review 6(1). 58-69. 
Stryker, Sheldon \& Kevin D. Vryan. 2006. The symbolic interactionist frame. In John Delamater (ed.) Handbook of social psychology, 3-28. New York: Springer.

Summers, John O. \& Donald H. Granbois. 1977. Predictive and normative expectations in consumer dissatisfaction and complaining behavior. Advances in Consumer Research 4(1). $155-158$.

Sung, Kang-Hoon \& Sora Kim. 2014. I want to be your friend: The effects of organizations' interpersonal approaches on social networking sites. Journal of Public Relations Research 26(3). 235-255.

Swan, John E., I. Fredrick Trawick \& Maxwell G. Carroll. 1982. Satisfaction related to predictive, desired expectations: a field study. In Ralph L. Day \& J. Keith Hunt (eds.), New Findings on Consumer Satisfaction and Complaining, 15-22. Bloomington, IN Indiana University Press.

Thomlison, T. Dean. 2000. An interpersonal primer with implications for public relations. In John A. Ledingham \& Stephen D. Bruning (eds.), Public relations as relationship management: A relational approach to the study and practice of public relations, 177-203. Mahwah, NJ: Lawrence Erlbaum Associates.

Van Eerde, Wendelien, \& Henk Thierry. 1996. Vroom's expectancy models and work-related criteria: A meta-analysis. Journal of Applied Psychology, 81. 575-586.

Walker, Lorraine Olszewski \& Kay Coalson Avant. 2011. Strategies for theory construction in nursing. 5th edition. Upper Saddle River: Prentice Hall. 
Westhues, Martina \& Sabine Einwiller. 2006. Corporate foundations: Their role for corporate social responsibility. Corporate Reputation Review 9(2). 144-153.

Wettstein, Florian., \& Dorothea Baur. 2016. "Why should we care about marriage equality?" Political advocacy as a part of corporate responsibility. Journal of Business Ethics, 138(2), 199-213.

Wigfield, Allan \& Jacquelynne S. Eccles. 2000. Expectancy-value theory of achievement motivation. Contemporary Educational Psychology 25(1). 68-81.

Wigfield, Allan, Stephen Tonks, \& Susan Lutz Klauda. 2009. Expectancy-value theory. In Kathryn R. Wentzel \& Allan Wigfield (eds.). Handbook of Motivation at School, 55-76. New York, NY: Routledge.

Woodruff, Robert B., Ernest R. Cadotte \& Roger L. Jenkins. 1983. Modeling consumer satisfaction processes using experience-based norms. Journal of Marketing Research 20(3). 296-304.

Zeithaml, Valarie A., Leonard L. Berry \& A. Parasuraman. 1993. The nature and determinants of customer expectations of service. Journal of the Academy of Marketing Science 21(1). 112.

Zeithaml, Valarie A., A. Parasuraman, \& Leonard L. Berry. 1990. Delivering quality service. New York: Free Press. 